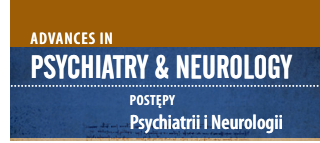

Correspondence to:

Olga Shulga

Volyn Regional Clinical Hospital

Prezydenta Hrushevskoho Ave, 21

Lutsk, Volyn Region

43000 Lutsk, Ukraine

e-mail: shulgaolga@ukr.net

Submitted: 26.12 .2018

Accepted: 03.11.2019

\section{COEXISTENCE OF EMOTIONAL REACTIONS AND ATROPHIC BRAIN CHANGES IN PATIENTS WITH CLINICALLY ISOLATED SYNDROME OF MULTIPLE SCLEROSIS}

\author{
Olga Shulga', Ihor Vydyborets' ${ }^{1}$ Tetyana Mamchych² \\ 'Volyn Regional Clinical Hospital, Lutsk, Ukraine \\ 2Lesya Ukrainka Eastern European National University, Lutsk, Ukraine
}

\begin{abstract}
Purpose: Atrophic processes of the brain affect the quality of life of patients whose cognitive functions and daily activity are already affected at the stage of the clinically isolated syndrome (CIS) of multiple sclerosis (MS). It is possible that in addition to pathogenic processes, the patient's emotions at the diagnostic stage can coexist with the course of the disease. We have evaluated the coexistence of emotional reactions in patients with CIS with the formation of atrophic brain changes in patients with MS as well as their association with the functional disability of the patient.

Methods: Thirty patients were examined at the CIS stage and during a repeated clinical attack of MS. The patient's emotional reaction was assessed at the time of the CIS diagnosis and one week later. For the estimation of atrophic processes of the brain, according to the MRI data on its dynamics, 23 linear parameters and 14 indices were used.

Results: The corpus callosum index was the most significant area of brain atrophy in a repeated attack of MS. There was a strong correlation between the negative emotional response to the diagnosis (shock and denial) and the degree of atrophy of the corpus callosum during repeated clinical attack of the disease as well as with a greater functional failure of the patient. Patients who reported experiencing anxiety or relief did not show increased atrophy.

Conclusions: The emotional response in the form of shock or denial of the diagnosis coexists with corpus callosum atrophy. The patient's emotional background affects the prognosis and the level of functional disability during the repeated clinical attack.
\end{abstract}

Key words: disability, multiple sclerosis, atrophy, clinically isolated syndrome, emotional reaction.

\section{INTRODUCTION}

Clinically isolated syndrome (CIS) signals the first clinical attack of multiple sclerosis (MS). It is considered as a monophasic clinical episode, the symptoms of which are reported by a patient with visible objective signs of focal or multifocal inflammatory demyelinating damage to the central nervous system. The symptoms of CIS appear rapidly or subacutely, lasting over 24 hours without fever or signs of an infectious process in a patient who has not showed MS symptoms. Usually, clinical signs of MS depend on the anatomical location of the foci/focus of demyelination and are manifested as unilateral neuritis of the optic nerve, focal supratentorial or brainstem, cerebellar syndrome or partial myelopathy $[1,2]$. MS will develop only in $30 \%$ to $70 \%$ of patients with CIS [3].
MS is a chronic dysimmune disease of the nervous system, a leading cause of nontraumatic disability in middle-aged adults. Over 2.3 million individuals worldwide suffer from MS [4]. In the early stages of the condition, the quality of patient's life, cognitive functions, everyday activity and working ability decrease compared to healthy individuals. This is partly provoked by the atrophic processes of the brain and causes considerable social and economic costs [5].

Brain atrophy in healthy adults has been reported to constitute $0.1-0.5 \%$ every year due to age, while in patients with MS it is $0.5-1.35 \%$ per year $[6,7]$. The atrophic processes of the brain occur at the stage of CIS. In particular, in patients with CIS against a background of disease-modifying treatment, a higher level of brain atrophy promotes the progression into MS over two years [8], as compared to those with a lower degree of atrophy. The sit- 
uation with CIS and MS is unpredictable because it is impossible to foresee the involvement of functional systems and the degree of the damage caused by the disease.

In the last decade, studies of CIS and MS have focused on the quality of life of patients, as well as non-motor symptoms of the disease, such as fatigue, pain and cognitive impairment $[9,10]$. At the same time, little attention has been paid to emotional reactions, which are an integral part of human experience, and are observed from the very beginning of the disease.

The nature of the interaction of emotions with MS has not been previously defined. Emotional abnormalities can be a consequence of the disease, a comorbid condition, or a combination of the two. Neuroimaging techniques partially explain the probable relationship between emotional reactions and anatomical structures of the brain, but further research is required. For example, anger and depression mechanisms may be a direct consequence of the demyelination of the links between the amygdala, basal ganglia and medial prefrontal cortex [11]. Another structure that is related to emotions and processes of demyelination is the corpus callosum (CC), since it has connections with adjacent limbic brain formations. Thus, the median and lateral longitudinal bands are associated with the upper surface of the CC, while the transparent partition and the cerebral artery are associated with the lower surface of the CC. Thus, it is possible that the interactions between the subconscious and the conscious psychic spheres also occur through the CC [12].

The nature of emotional reactions depends on the biological, psychological and also sociological factors. It is possible that emotional expression will affect the adaptation of patients to the illness and subsequent changes in lifestyle.

The sequence of MS processes is also unclear, which causes certain emotions in patients in the first stages of the disease. Typical acute responses include resentment, anger or guilt which are associated with a reduced psychological, physical or social involvement in life [13].

It has been established that emotions can influence the course of chronic diseases, response to therapy and treatment outcomes. Shock, denial, anxiety, anger or relief are most common typical emotional reactions to the diagnosis of clinically isolated syndrome [13].

The dynamic monitoring of atrophic processes in the brain in CIS and MS is also complicated due to the short-term functioning magnetic resonance imaging (MRI)-scanners. Thus, the number of scientific works dedicated to CIS is insufficient. The investigation of emotional reactions in CIS, their connection and possible coexistence with brain atrophy and functional inability, have not been previously studied.

The aim of the study was to determine the potential coexistence of emotional reaction in patients with CIS with the formation of atrophic brain changes in patients with MS and establish their connection with the patient's functional disability.

\section{METHODS}

This is the first ever investigation of its kind. The research took the form of an observational, prospective, double (a patient, a researcher) examination of patients with a clinically isolated syndrome of MS. The research involved patients treated in a neurological department, diagnosed with clinically isolated syndrome of multiple sclerosis in the period from 1 March 2013 to 1 March 2018 and also having a diagnosis of CIS.

Criteria for involvement in the research:

- age of participants: 18-55 years;

- diagnoses of CIS and MS established according to McDonald criteria 2010 with Polman modification [14];

- participants in the research must not have had any other neurological, mental diseases or any diseases causing foci in the brain;

- objective investigation must have been performed prior to an intravenous course of methylprednisolone;

- an MRI of the brain must have been carried out after the assessment of the patient's objective status on the same scanner;

- absence of claustrophobia;

- body mass $\geq 40 \mathrm{~kg}$;

- primary-progressive MS (progressing over the course of a year);

- absence of alcohol or drug addiction;

- initially isolated spinal symptoms in a patient;

- low level of anxiety as a personality trait by the Spielberger State-Trait Anxiety Inventory (STAI) scale [16];

- minimum duration of monitoring was 3 months;

- patients gave their consent to the participation in the investigation.

Any condition not meeting the requirements of inclusion criteria was considered a criterion for exclusion.

Primary goal: to estimate the coexistence of a patient's emotional reaction to a CIS diagnosis with atrophic processes in the brain in repeated clinical attack and disability by EDSS scale [15].

Secondary goals: to assess the condition of atrophic processes in the brain at the CIS stage and to assess the dynamics of atrophic processes in the brain in repeated clinical attacks.

Design of the investigation is presented in Figure 1.

To avoid ambiguities, neurological examination was performed by one certified specialist according to the EDSS scale. To reduce the possible influence of personality trait on the estimation of emotional reaction, all patients underwent testing with the Spielberger StateTrait Anxiety Inventory (STAI) scale [16]. Emotions 


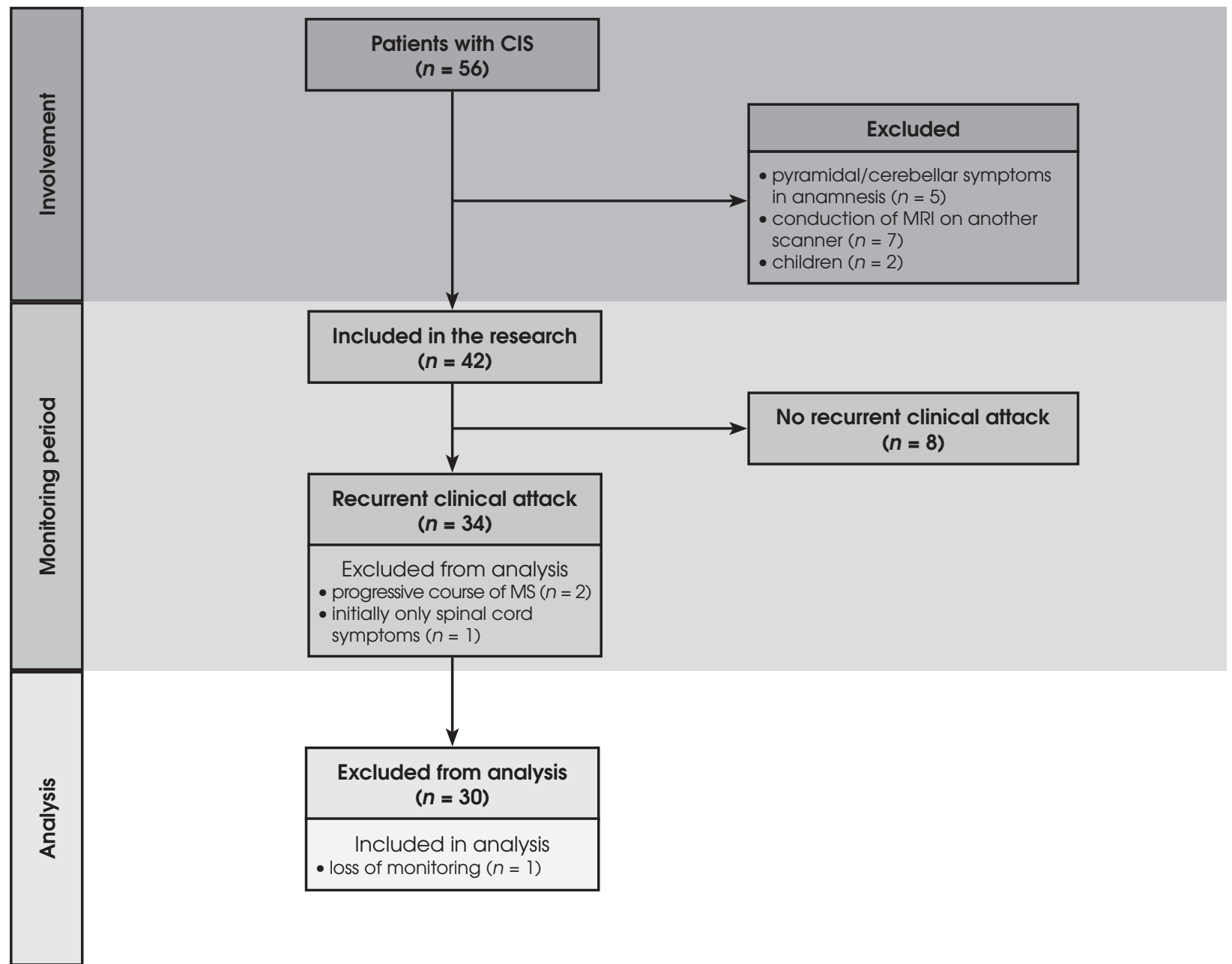

Figure 1. Design of the investigation

at the stage of CIS were evaluated through a patient interview. To test the reliability of the emotional reaction, the test-retest method was used. Patients independently determined the dominant emotion at the stage of diagnosis of clinically isolated syndrome. A reassessment of the emotional response took place after 7 days. To decrease possible dissimilarities for MRI results, the examination was performed on the same scanner; calculations were performed by one specialist applying one technique.

Safety: routine laboratory investigations (hematological, biochemical), including liver function tests and creatinine, urea measurements were performed during each visit before conducting an MRI scan of the brain.

An MRI of the brain was performed on a $1.5 \mathrm{~T}$ scanner Toshiba Titan Octave, applying the following modes of operation: T1 (repetition time $800 \mathrm{~ms}$, echo time $12 \mathrm{~ms}$, slice thickness $5 \mathrm{~mm}$ ), T2 (repetition time $5992 \mathrm{~ms}$, echo time $105 \mathrm{~ms}$, slice thickness $4 \mathrm{~mm}$ ), FLAIR (repetition time $9000 \mathrm{~ms}$, echo time $90 \mathrm{~ms}$, slice thickness $4 \mathrm{~mm}$ ), in axial, sagittal and coronal projections. Gadolinium contrast medium (concentration $1 \mathrm{mmol} / \mathrm{ml}$ ) was calculated as $0.1 \mathrm{ml} / \mathrm{kg}$ of body mass. The radiologist was not told the diagnosis or clinical data of a patient for calculation of the number, localization of foci and conduction of linear measurements of brain atrophy. T2-weighted and T1-weighted foci were estimated according to localization as periventricular, infratentorial, juxtacortical and cortical as well as "black holes" on T1-mode. The foci, which accumulated contrast, were also estimated. To assess atrophic processes, measurement of 23 linear parameters was performed for each patient twice during the first and repeated clinical attack. In addition, 14 indices were calculated for each MRI, namely corpus callosum index, width of lateral ventricles (right and left), width of the III ventricle, frontal atrophy index, bicaudate index, index of medial structures, Evans' index, Huckman index, ventricular parieto-occipital index and ventricular temporal index [17-22]. To conduct linear measurements, a RadiAnt DICOM Viewer, which is free and available online (https://www.radiantviewer. com/), was used. 

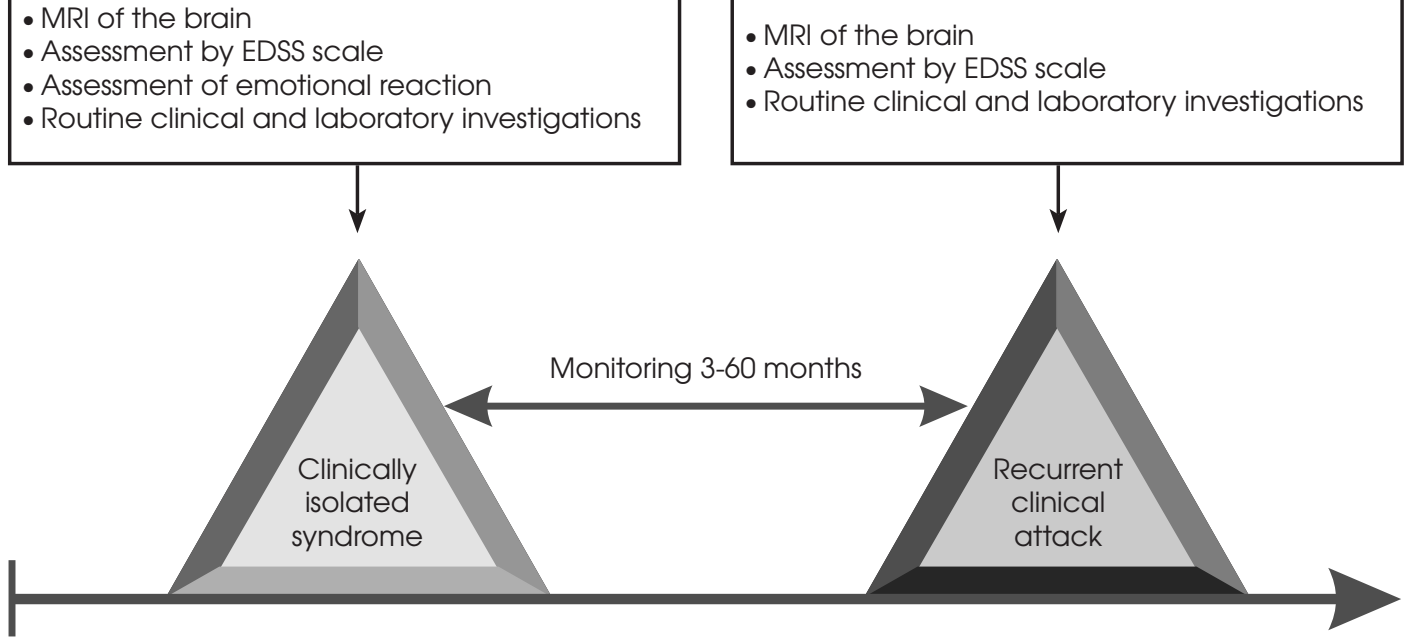

- MRI of the brain

- Assessment by EDSS scale

- Routine clinical and laboratory investigations

Figure 2. Stages of the investigation

Table 1. Demographic characteristics of patients

\begin{tabular}{|c|c|}
\hline Characteristics & Index \\
\hline Age of examined individuals at the time of CIS (years) & $32.07 \pm 8.54$ \\
\hline Males/Females, $n(\%)$ & $3(10) / 27(90)$ \\
\hline \multicolumn{2}{|l|}{ Onset, $n$ (\%): } \\
\hline Monofocal & $12(40 \%)$ \\
\hline Multifocal & $18(60 \%)$ \\
\hline \multicolumn{2}{|l|}{ Points by functional scales (EDSS): } \\
\hline Visual & $0.833 \pm 1.09$ \\
\hline Pyramidal & $1.33 \pm 0.96$ \\
\hline Cerebellar & $1.33 \pm 1.12$ \\
\hline Bowel/bladder & $0.23 \pm 0.63$ \\
\hline Cerebral disorders & $0.17 \pm 0.38$ \\
\hline Point by EDSS scale at the time of CIS & $2.98 \pm 0.55$ \\
\hline Time from CIS to the repeated attack (months) & $6.33 \pm 3.467$ \\
\hline Point by EDSS scale at the time of the repeated attack & $2.92 \pm 0.081$ \\
\hline Duration of monitoring (months) & $33.10 \pm 12.81$ \\
\hline
\end{tabular}

EDSS - Expanded Disability Status Scale, CIS - clinically isolated syndrome

\section{Statistical analysis}

Statistical analysis was performed by means of the SPSS for Windows software; standard descriptive statistics were used. To analyse categorical data, Pearson's $\chi^{2}$ test was used. The results $p<0.05$ were statistically significant. Spearman's nonparametric correlation coefficient was used for the estimation of value and dependence between the rankings of variables. Unifactor dispersion analysis of variance (ANOVA) was used for multivariate analysis. To assess the reliability of emotional reaction, an estimation of their reproduction by means of a test-retest of analysis and determination of the coefficient of internal constancy Cronbach's a (at a level more than 0.70) - was used.

\section{RESULTS}

The research involved three stages. During the first stage of monitoring, 56 patients diagnosed with CIS were assessed. Considering the inclusion criteria, 14 individuals were excluded before the monitoring stage (among them two children under 18, five individuals with pyramidal and/or cerebellar symptoms in anamnesis who had not previously seen a neurologist, and seven patients for whom MRI was performed on another scanner). At the monitoring stage, 8 patients out of 42 did not develop MS. Thirty patients were included in the analysis with the calculation of the indices. Schematically, the stages of the investigation are presented in Figure 2. Patients' demographic data $(n=30)$ are presented in Table 1 .

The emotional reaction of patients to a diagnosis of clinically isolated syndrome is presented in Figure 3. Patients with CIS most frequently experienced anxiety (18 patients $-60 \%$ ); shock was noted in 5 patients $(16.56 \%)$, complete denial of the diagnosis was observed in 4 individuals (13.33\%). A much smaller number of patients experienced relief (in two cases $-6.67 \%$ ), and grief (in one case $-3.33 \%)$ after receiving their diagnosis. For repeated testing (7 days after the initial test), 29 (96.67\%) patients gave identical responses. The correlation coefficient between the primary and the repeated tests $(r=0.9869)$ was above the minimum significant level, equal to 0.7 . Accordingly, patients noted identical emotions 7 days after the initial test and their re-evaluation yielded similar results. The results of the test-retest analysis showed a satisfactory score. The result of the estimation of internal constancy at the coefficient Cronbach's a was 0.993 .

MRI of the brain at CIS stage was performed, on average, in a period of seven days from the onset of symptoms and until an intake of glucocorticoids. Indices of at- 
Coexistence of emotional reactions and atrophic brain changes in patients with clinically isolated syndrome of multiple sclerosis

Table 2. Indices of brain atrophy

\begin{tabular}{|l|c|c|}
\hline & $\begin{array}{c}\text { Magnetic resonance imaging } \\
\text { at the time of CIS }\end{array}$ & $\begin{array}{c}\text { Magnetic resonance imaging } \\
\text { at the time of the repeated attack }\end{array}$ \\
\hline Corpus callosum index & $0.43 \pm 0.36$ & $0.4 \pm 0.32^{*}$ \\
\hline Index of frontal atrophy & $0.30 \pm 0.03$ & $0.30 \pm 0.06$ \\
\hline Index of medial structures & $0.17 \pm 0.02$ & $0.17 \pm 0.05$ \\
\hline The width of the right horn of the lateral ventricle & $4.50 \pm 4.14$ & $3.98 \pm 2.11$ \\
\hline The width of the left horn of the lateral ventricle & $3.33 \pm 2.90$ & $3.24 \pm 1.94$ \\
\hline The width of the Ill ventricle & $4.93 \pm 1.78$ & $5.37 \pm 2.09$ \\
\hline Evans' index & $0.25 \pm 0.03$ & $0.25 \pm 0.01$ \\
\hline Huckman index & $0.63 \pm 0.91$ & $0.41 \pm 0.07$ \\
\hline Bicaudate index & $0.11 \pm 0.02$ & $0.12 \pm 0.02$ \\
\hline Ventricular parietooccipital index, right & $0.29 \pm 0.20$ & $0.08 \pm 0.02$ \\
\hline Ventricular parietooccipital index, left & $0.08 \pm 0.02$ & $0.08 \pm 0.01$ \\
\hline Ventricular temporal index, right & $11.25 \pm 3.12$ & $11.14 \pm 3.54$ \\
\hline Ventricular temporal index, left & $10.28 \pm 2.08$ & $10.53 \pm 2.83$ \\
\hline
\end{tabular}

${ }^{*}$ Statistically significant $(p<0.0001)$

CIS - clinically isolated syndrome

rophy at the CIS stage and the repeated clinical attack are presented in Table 2. A statistically significant value at the level $p<0.001$ was determined only for the corpus callosum index. A statistically significant correlation between the values of "reaction" indices and total points on the EDSS scale was established by means of a $\chi^{2}$ test $(p<0.01)$. Table 3 shows frequencies for index value "reaction" and points on the EDSS scale.

Unifactor dispersion analysis of variance (ANOVA) was used for multivariate analysis to determine whether the values of the EDSS step and index were significantly different for various levels of the index "reaction". The influence of the factor levels on mean values of the EDSS index were established at the level of significance $p=0.05$ (it should be noted that we do not consider a proximate and ultimate causation). The data are presented in Table 4.

The hypothesis about the equality of medians of the EDSS index value for various levels of the factor "reaction" was also verified by means of the Kruskal-Wallis test but a statistically significant difference between the medians was not detected.

Patients were sorted by a decline of value of the "reaction" index.

Thus, marked emotional reaction manifested by shock is a negative prognostic factor for corpus callosum atrophy. Simultaneously, there was no significant difference for indices in patients with anxiety and relief.

\section{DISCUSSION}

One of the main drawbacks of the research is the insufficient number of patients involved. However, sampling is sufficient to estimate the results. Our study would

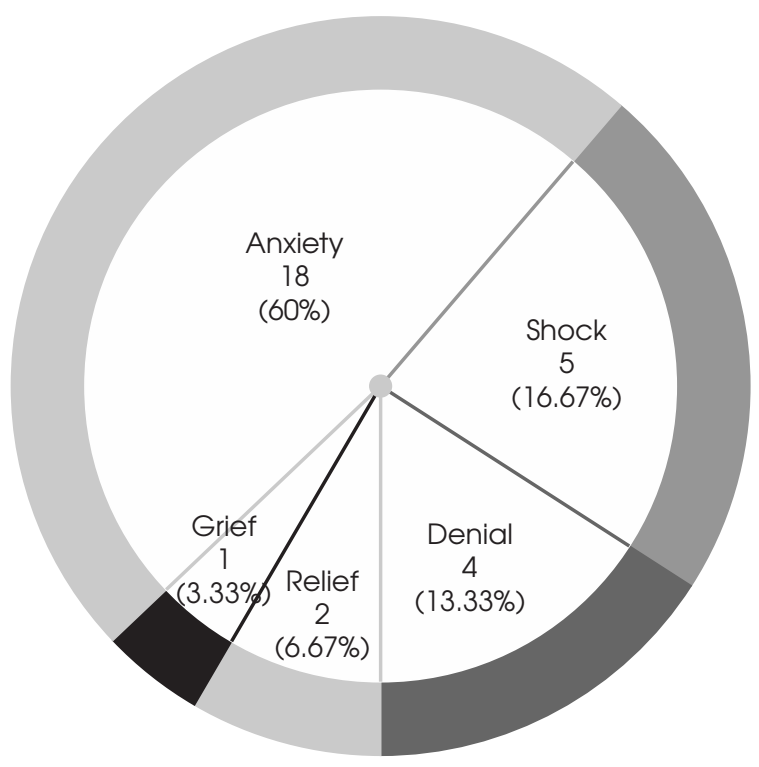

Figure 3. Emotional reaction of patients to a diagnosis of clinically isolated syndrome

Table 3. Functional disability in patients with various types of reaction

\begin{tabular}{|l|c|c|c|c|c|c|}
\hline \multirow{2}{*}{ Reaction } & \multicolumn{7}{|c|}{ Point by EDSS scale } \\
\cline { 2 - 7 } & $\mathbf{2}$ & $\mathbf{2 . 5}$ & $\mathbf{3}$ & $\mathbf{3 . 5}$ & $\mathbf{4 . 5}$ & Total \\
\hline Shock & 0 & 0 & 4 & 1 & 0 & 5 \\
\hline Denial & 1 & 1 & 1 & 1 & 0 & 4 \\
\hline Anxiety & 2 & 4 & 7 & 5 & 0 & 18 \\
\hline Relief & 0 & 1 & 0 & 1 & 0 & 2 \\
\hline Grief & 0 & 0 & 0 & 0 & 1 & 1 \\
\hline Total & 3 & 6 & 12 & 8 & 1 & 30 \\
\hline
\end{tabular}

EDSS - Expanded Disability Status Scale 
Table 4. Descriptive statistics for Expanded Disability Status Scale (EDSS) index for various levels of the index "Reaction"

\begin{tabular}{|l|c|c|c|c|c|c|}
\hline Reaction & Number & Mean & Lower margin & Upper margin & Min & Max \\
\hline Shock & 5 & 3.10 & 2.78 & 3.42 & 3.0 & 3.5 \\
\hline Denial & 4 & 2.75 & 2.40 & 3.10 & 2.0 & 3.5 \\
\hline Anxiety & 18 & 2.92 & 2.75 & 3.09 & 2.0 & 3.5 \\
\hline Relief & 2 & 3.00 & 2.49 & 3.51 & 2.5 & 3.5 \\
\hline Grief & 1 & 4.50 & 3.78 & 5.21 & 4.5 & 4.5 \\
\hline
\end{tabular}

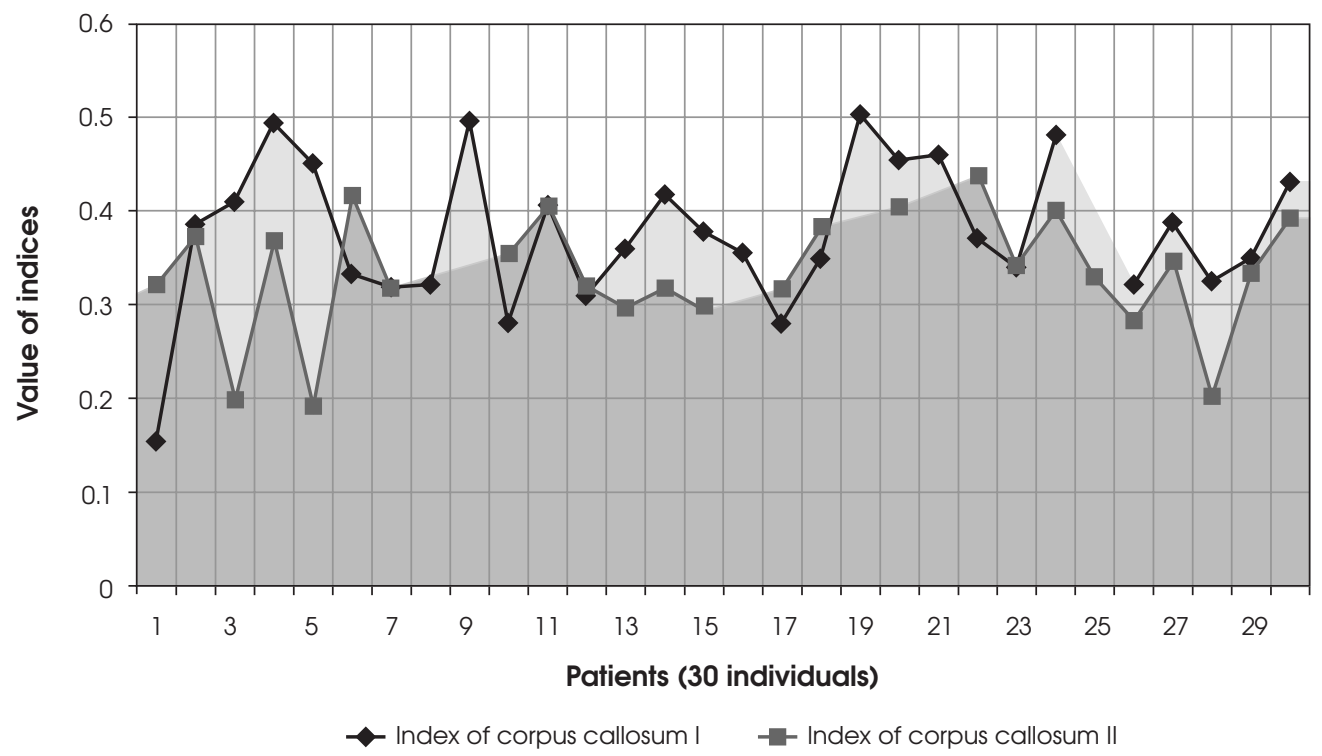

Figure 4. Indices of corpus callosum in dynamics

benefit from further large-scale epidemiological research looking at the patients' emotional status throughout the course of disease. The atrophy of the corpus callosum is more aggressive in the early stages of MS and decreases with disease duration [23]. Thus, our understanding of the timeframe of the atrophy process encourages early treatment at the initial stages of the disease, especially at the time of the CIS diagnosis. In addition, neurobiological research investigation, as well as functional MRI studies, may improve our knowledge of the coexistence of emotional states and inflammatory and degenerative processes in MS. These results can be partially explained by disconnection syndrome because CC is the largest white matter bundle, which connects cortical regions within the frontal, parietal, occipital and temporal lobes $[24,25]$. The studies of the neural basis of feelings are lagging behind, as feelings cannot be evaluated in animals. However, PET studies of emotions have proved that the activation and deactivation patterns of somatosensory cortex and brainstem depend on emotions [25]. In previous studies, we did not find any information about why one emotion could coexist with corpus callosum at- rophy while others did not. These results require further investigations. Another issue which should be considered is the absence of a unique assessment tool for the screening of emotions.

Further, the study would benefit from assessing the influence of psychological rehabilitation and, likely, drug correction of emotional disorders at the CIS stage. Finally, we concede that the neuroimaging analysis was basic and descriptive and that using volumetric neuroimaging methods such as voxel-based morphometry would be more applicable for a better-understanding of the coexistence of emotions, functional disability and brain changes throughout the course of the disease.

The results of our investigation can be used for planning and optimizing medical aid to patients with CIS and MS. In the future, it will be expedient to conduct large-scale investigations estimating the possible coexistence of emotions at the CIS stage and in the dynamics of the disease combined with psychotherapy, evaluation of atrophic processes, and the effects of their combination on treatment efficacy. 


\section{CONCLUSIONS}

It has been established that emotional reactions coexist with prognoses and functional inability during re- peated clinical attack. Structural changes in the corpus callosum in the second clinical attack are connected, to a certain extent, to the patient's emotional response to the diagnosis.

\section{Conflict of interest}

Absent.

\section{Financial support}

Absent.

\section{References}

1. Thompson AJ, Banwell BL, Barkhof F, et al. Diagnosis of multiple sclerosis: 2017 revisions of the McDonald criteria. Lancet Neurol 2018; 17: 162-173.

2. Montalban X, Gold R, Thompson AJ, et al. ECTRIMS/EAN guideline on the pharmacological treatment of people with multiple sclerosis. Eur J Neurol 2018; 25: 215-237.

3. Miller D, Barkhof F, Montalban X, Thompson A, Filippi M. Clinically isolated syndromes suggestive of multiple sclerosis, part I: natural history, pathogenesis, diagnosis, and prognosis. Lancet Neurol 2005; 4: 281-288.

4. Multiple Sclerosis International Federation. Atlas of MS Database Data Export: Number of People with MS, 2013. Available at: http://www.atlasofms.org.

5. Giovannoni G, Butzkueven H, Dhib-Jalbut S, et al. Brain health: time matters in multiple sclerosis. Mult Scler Relat Disord 2016; 9 Suppl 1: S5-S48.

6. De Stefano N, Sprenger T, Freedman M, et al. Including threshold rates of brain volume loss in the definition of disease activity-free in multiple sclerosis using fingolimod phase 3 data. In: Proceedings of Joint ACTRIMS-E CTRIMS Meeting. Boston, MA, USA; 2014. Available at: http://www.abstractstosubmit.com/msboston2014/eposter/main. php? do1/4YToyOntzOjU6Im1vZHVslitzOjY6ImRldGFpbCI7czo4OiJkb2N1bW VudCI7a To3NzQ7fQ1/4 1/4\&.

7. De Stefano N, Stromillo ML, Giorgio A, et al. Establishing pathological cut-offs of brain atrophy rates in multiple sclerosis. J Neurol Neurosurg Psychiatry 2016; 87: 93-99.

8. Kalincik T, Vaneckova M, Tyblova M, et al. Volumetric MRI markers and predictors of disease activity in early multiple sclerosis: a longitudinal cohort study. PLoS One 2012; 7: e50101.

9. Hynčicová E, Vyhnálek M, Kalina A, et al. Cognitive impairment and structural brain changes in patients with clinically isolated syndrome at high risk for multiple sclerosis. J Neurol 2017; 264: 482-493.

10. Diker S, Has AC, Kurne A, et al. The association of cognitive impairment with gray matter atrophy and cortical lesion load in clinically isolated syndrome. Mult Scler Relat Disord 2016; 10: 14-21.

11. Rabins PV, Brookes BR, O'Donnell P, et al. Structural brain correlates of emotional disorder in multiple sclerosis. Brain 1986; 109: 585-597.

12. Fabri M, Pierpaoli C, Barbaresi P, Polonara G. Functional topography of the corpus callosum investigated by DTI and fMRI. World J Radiol 2014; 6: 895-906.

13. Kalb R, Reitman N (eds.). Multiple Sclerosis: A Model of Psychosocial Support. 5th ed. National Multiple Sclerosis Society; 2012. Available at: http://www.nationalmssociety.org/NationalMSSociety/media/MSNationalFiles/ Brochures/Book-A-Model-of-Psychosocial-Support.pdf.

14. Polman CH, Reingold SC, Banwell B, et al. Diagnostic criteria for multiple sclerosis: 2010 revisions to the McDonald criteria. Ann Neurol 2011; 69: 292-302.

15. Kurtzke JF. Rating neurologic impairment in multiple sclerosis an expanded disability status scale (EDSS). Neurology 1983; 33: 1444-1452.

16. Hreben NF. Psychological tests for professionals. Sovremennaya shkola, Minsk 2007; p. 496.

17. Abdelalim AM, Metwally LIA, Ahmed SM, et al. The use of corpus callosum index in the measurement of brain atrophy in multiple sclerosis. Egypt J Neurol Psychiat Neurosurg 2010; 47: 633-637.

18. Missori $\mathrm{P}$, Currà A. Progressive cognitive impairment evolving to dementia parallels parieto-occipital and temporal enlargement in idiopathic chronic hydrocephalus: a retrospective cohort study. Front Neurol 2015; 6: 15.

19. Naud A, Schmitt E, Wirth M, Hascoet JM. Determinants of indices of cerebral volume in former very premature infants at term equivalent age. PLoS One 2017; 12: e0170797.

20. Figueira F, Santos V, Figueira G, Silva A. A practical method for long-term follow-up in multiple sclerosis. Arq Neuropsiquiatr 2007; 65 (4-A): 931-935.

21. Menendez M, Arias-Carrión O. Indices of regional brain atrophy: formulae and nomenclature. Cureus 2015; 7: e295. 
22. Kizlaitienandedot R, Kaubrys G, Giedraitienandedot N, et al. Composite marker of cognitive dysfunction and brain atrophy is highly accurate in discriminating between relapsing-remitting and secondary progressive multiple sclerosis. Med Sci Monit 2017; 23: 588-597.

23. Granberg T, Martola J, Bergendal G, et al. Corpus callosum atrophy is strongly associated with cognitive impairment in multiple sclerosis: results of a 17-year longitudinal study. Mult Scler 2015; 21: 1151-1158.

24. Catani M, Ffytche DH. The rises and falls of disconnection syndromes. Brain 2005; 128 Pt 10: 2224-2239.

25. Damasio AR, Grabowski TJ, Bechara A, et al. Subcortical and cortical brain activity during the feeling of self-generated emotions. Nat Neurosci 2000; 3: 1049-1056.

\section{Ministerstwo Nauki} i Szkolnictwa Wyższego
Praca dofinansowana z zadania: Publikowanie artykułów naukowych w języku angielskim w kwartalniku Advances in Psychiatry and Neurology/ Postępy Psychiatrii i Neurologii jest finansowane w latach 2018-2019 w ramach umowy nr 707/P-DUN/2018 ze środków Ministra Nauki i Szkolnictwa Wyższego przeznaczonych na działalność upowszechniającą naukę. 